\title{
A Qualitative Study on the Negative Emotions of Mothers during Chemotherapy of Their Children with Malignant Brain Tumors
}

\author{
Zhihuan Zhou, Lan Bai*, Qinqin Zhao \\ Department of Neurosurgery, Sun Yat-sen University Cancer Center, Guangzhou, China \\ Email: *bailan@sysucc.org.cn
}

How to cite this paper: Zhou, Z.H., Bai, L. and Zhao, Q.Q. (2021) A Qualitative Study on the Negative Emotions of Mothers during Chemotherapy of Their Children with Malignant Brain Tumors. Journal of Cancer Therapy, 12, 1-9.

https://doi.org/10.4236/jct.2021.121001

Received: November 26, 2020

Accepted: January 11, 2021

Published: January 14, 2021

Copyright $\odot 2021$ by author(s) and Scientific Research Publishing Inc. This work is licensed under the Creative Commons Attribution International License (CC BY 4.0).

http://creativecommons.org/licenses/by/4.0/

\begin{abstract}
Objective: To explore the negative emotions of mothers during chemotherapy of their children with malignant brain tumors. Methods: The phenomenological method for qualitative studies was adopted; convenience sampling was used to conduct semi-structured interviews to the mothers of 9 children with malignant brain tumors who received chemotherapy from June 2019 to December 2019; the Colaizzi 7-step analytical method was implemented to collate and analyze the original data. Results: The results were summarized into six subjects: stressed, exhausted because of trying to control everything in home care, prone to excessive care, financially burdened, desperate for knowledge of patient care, and desperate for psychosocial support. Conclusions: Understanding the real experiences and inner feelings of mothers during chemotherapy of their children with malignant brain tumors is helpful for medical staff to learn about the psychological distress and needs of mothers of children with malignant brain tumors, so as to give them psychological support and even social support, and help the mothers and the families of children with malignant brain tumors get through a special period.
\end{abstract}

\section{Keywords}

Children, Brain Tumor, Mother, Negative Emotions, Qualitative Study

\section{Introduction}

Childhood central nervous system tumor is the most common solid tumor only second to leukemia. It features high degree of malignancy and high mortality [1] [2]. Generally, a combined therapy of surgery, radiotherapy and chemotherapy is recommended. Considering the high mortality and the reduced quality of life 
in survivors due to different degrees of developmental disorders caused by postoperative radiotherapy and chemotherapy, childhood central nervous system tumor is an unexpected critical incident for families and even the society. Studies abroad show that [3] mothers of children with cancer are more vulnerable to post-traumatic stress disorder than general people and suffered more negative emotions such as anxiety and depression [4]. Mothers not only need to assume the role of caregiver, but also need to bear a series of burdens: anxiety, social role contradictions, and family relationship maintenance [5]. In China, there are few studies on parents and families of children with cancer, and even fewer studies on parents and families of children with brain tumors.

The purpose of surgical treatment of malignant brain tumors in children is to remove the tumor and restore the cerebrospinal fluid circulation channels as far as possible to relieve the symptoms caused by obstructive hydrocephalus and provide time and possibility for subsequent radiotherapy and chemotherapy [6]. Subsequent chemotherapy means that children need to get in/out of hospital repeatedly in a long term, and their mothers, often as the daily caregivers of the children, may easily feel heavily burdened since nobody can listen to them while they take care of a sick child, especially in participants where the children have poor functions [7]. This study is aimed at understanding the inner experience and needs of mothers during chemotherapy of children with malignant brain tumors using phenomenological methods. It is reported as follows.

\section{Objects and Methods}

\subsection{Research Objects}

In this study, convenience sampling was adopted to select the mothers of 9 children with malignant brain tumors that received chemotherapy at the department of neuro-oncology of a specialized oncology hospital in Guangzhou from June 2019 to December 2019. Inclusion criteria for children: 1) 0 - 18 years old; 2) diagnosed with malignant central nervous system tumor by pathology; 3 ) received chemotherapy at our hospital. Inclusion criteria for mothers: 1) normal communication and understanding skills; 2) as the main contact person during the hospitalization of her child; 3 ) agreed to get interviewed and recorded. The sample size was determined by the fact that the data of the interviewees appeared repeatedly and that the data analysis no longer presented new subjects. In addition to one Taobao shopkeeper that continued to work, the remaining 8 mothers all suspended their work after their child became sick. The details are shown in Table 1.

\subsection{Research Method}

The phenomenological experience in this study is the emotional experience of mothers during chemotherapy of their children with malignant brain tumors. Each respondent is called a participant in this study. The researchers used semistructured interviews. Here is the outline: "Please talk about what happened when 
Table 1. General information of respondents $(n=9)$.

\begin{tabular}{|c|c|c|c|c|c|c|c|c|c|}
\hline $\mathrm{S} / \mathrm{N}$ & Age & $\begin{array}{l}\text { Education } \\
\text { background }\end{array}$ & $\begin{array}{l}\text { Marital } \\
\text { status }\end{array}$ & $\begin{array}{c}\text { Monthly } \\
\text { household } \\
\text { income (RMB) }\end{array}$ & Pre-event job & $\begin{array}{l}\text { Age of } \\
\text { child }\end{array}$ & $\begin{array}{l}\text { Only child } \\
\text { or not }\end{array}$ & Diagnosis & Symptoms of child \\
\hline 1 & 32 & Junior college & Married & 3000 & Fisher & 9 & Yes & Right frontal lobe PNET & $\begin{array}{c}\text { Myodynamia of both } \\
\text { lower extremities }\end{array}$ \\
\hline 2 & 35 & $\begin{array}{c}\text { Technical } \\
\text { secondary school }\end{array}$ & Married & 5000 & Clerk & 12 & Yes & $\begin{array}{l}\text { Sellar malignant } \\
\text { mixed germinoma }\end{array}$ & $\begin{array}{l}\text { Growth retardation, } \\
\text { diabetes insipidus }\end{array}$ \\
\hline 3 & 42 & Junior college & Married & 10,000 & Self-employed & 14 & No & $\begin{array}{c}\text { Cerebrocentric } \\
\text { disseminated PNET }\end{array}$ & $\begin{array}{l}\text { Myodynamia of left } \\
\text { upper extremity, blind }\end{array}$ \\
\hline 4 & 40 & Middle school & Married & 2000 & Housewife & 8 & No & $\begin{array}{l}\text { Suprasellar and pineal } \\
\text { malignant mixed } \\
\text { germinoma }\end{array}$ & $\begin{array}{l}\text { Growth retardation, } \\
\text { diabetes insipidus, } \\
\text { blurred vision }\end{array}$ \\
\hline 5 & 38 & Junior college & Married & 5000 & Civil servant & 8 & No & $\begin{array}{l}\text { Cerebellar brainstem } \\
\text { medulloblastoma }\end{array}$ & $\begin{array}{l}\text { Growth retardation, } \\
\text { walking imbalance }\end{array}$ \\
\hline 6 & 40 & Middle school & Married & 3000 & Clerk & 12 & No & $\begin{array}{l}\text { Sellar malignant mixed } \\
\text { germinoma }\end{array}$ & $\begin{array}{l}\text { Growth retardation, } \\
\text { diabetes insipidus }\end{array}$ \\
\hline 7 & 37 & Middle school & Divorced & 2000 & Housewife & 7 & Yes & $\begin{array}{l}\text { Fourth ventricle } \\
\text { medulloblastoma }\end{array}$ & Growth retardation \\
\hline 8 & 37 & University & Married & 8000 & $\begin{array}{l}\text { Community } \\
\text { doctor }\end{array}$ & 12 & Yes & $\begin{array}{c}\text { Cerebellar anaplastic } \\
\text { oligodendroglioma }\end{array}$ & Growth retardation \\
\hline 9 & 30 & Middle school & Married & 3000 & Housewife & 8 & No & $\begin{array}{c}\text { Cerebellar } \\
\text { neuroblastoma }\end{array}$ & $\begin{array}{l}\text { Myodynamia of both } \\
\text { upper extremities, } \\
\text { walking imbalance }\end{array}$ \\
\hline
\end{tabular}

your child was found ill.", "How do you take care of your child during chemotherapy?", "What are the difficulties while you take care of your child?", "What makes you most stressed?", "What do you when you feel sad?", "What help do you need most? How do you want to get it?", The researchers continued the interview according to the response of the participant, and used instructive and clarifying techniques to encourage her to continue, e.g. "Would you please talk more about it?" or "You mean...?"

The researchers made clear the purpose of the study to the subjects, and signed an informed consent with each object. The interviews took place in the conversation room. The interview time was due before the children received chemotherapy. Each participant was interviewed for about 60 minutes, the entire process recorded. The researchers listened to and recorded the content and meanwhile observed the changes of the subject's expression. After that, the recordings were transcribed into texts, and analyzed with Colaizzi analytical method. The researchers carefully recorded and read all the interview materials to extract meaningful statements consistent with the mothers' emotional experience, and then summarized and refined these statements to further form subjects and subject groups. A complete description was provided by relating subjects to phenomena. 
Finally, the results were returned to the research objects to further verify the authenticity of the content.

\section{Results}

\subsection{Subject 1: Stressed}

\subsubsection{Sad}

Into the chemotherapy stage, all mothers already accepted the fact that their child suffered a malignant brain tumor, but felt very painful to think of the fact that their child was ill. participant 2: "I'd rather I were sick."; participant 8: "If only I were sick." Quite a few mothers still had unrealistic hopes. participant 3: "Sometimes when I wake up, I wish this is a dream".

\subsubsection{Guilty}

Since the etiology of malignant brain tumors is unknown, some children was diagnosed in a treatment for developmental retardation. And 5 participants saw developmental retardation in this group. So the mothers had a strong sense of self-accusation: participant 4: "I am unlettered, so I thought he just looked smaller than his peers." participant 6: "Does his illness have anything to do with XXX I ate while I was pregnant?" participant 5: "If only I had found earlier that something was wrong with him."

\subsection{Subject 2: Exhausted Because of Trying to Control Everything in Home Care}

\subsubsection{Playing Multiple Roles}

The mothers played multiple roles such as mother, nurse and cleaner in intermissions of chemotherapy, so their life was busy, chaotic and compact. Participant 1: "I dare not let my child get out of bed alone. So I get up early to support him. Soon, it is noon. I'm busy all day. I have no time to rest." participant 6: "His father need go to work. At home, I have to cook and feed my son. At hospital, I can use food delivery service, and ask the staff to help me take my son to the toilet." participant 8: "I realized what a happy life I lived before my child became ill. Back then, I did little housework, but easily felt frustrated. Now, I know the previous frustration is not frustration at all. This is real frustration."

\subsubsection{Unable to Take Care of the Other Family Members}

The mothers needed to keep an eye on the physical and mental changes of their children, and follow the guidance manual for home care for children with cancer. In the absence of support from others, the mothers were unable to take into account the needs of other children and husband, for which they felt irritable, sorrowful and incapable. participant 4: "My elder child was gonna take the senior high school entrance examination, but I had no choice." participant 5: "My elder child is grown-up. My major task is to take care of the ill one." participant 9: "My younger child is still small. I left him in my hometown. I don't even have the time to see him. I rent a house in Guangzhou to treat my ill child.” 


\subsection{Subject 3: Prone to Excessive Care}

\subsubsection{Worried about the Inconsistency among the Mindsets of Family Members}

The inconsistency among the mindsets of family members made the mother, as the primary caregiver, stressed. And some mothers even conflicted with other family members because of smoking. Participant 4: "After my child got sick, I try to provide a safe environment for him. But my dad, my uncle and sometimes my husband's friends smoke inside. I don't have the heart to ask them to get out. So I just prevent my child from coming downstairs." participant 1: "His grandpa and dad smoke. Now that my child got ill, they smoked outside. They also took my child to temples for worship. They are superstitious, but I cannot change it! I suffer chest distress for this."

\subsubsection{Worried about Infection}

For the safety of the child's environment, some mothers asked family members to wear masks at home in participant that the child is infected at home. participant 5: "Everyone wears a mask at home except when he is asleep." participant 6: "I don't know what on earth I should do to prevent infection. I don't let him go out for fear of infection." participant 7: "His uncle's child got vaccinated. Then, I told his uncle not to see my child." participant 8: "I take his temperature from time to time."

\subsection{Subject 4: Financially Burdened}

Most mothers were financially burdened by the high cost of surgery, radiotherapy, chemotherapy and other treatments and various adjuvant treatments. participant 7: "I got divorced. His dad knows he is ill, but refuses to give us money. Now, my boyfriend supports me somewhat. But God knows how long that can last. Everyone thinks for himself, right?" participant 9: "Now, the family is supported by my husband's salary. The cost of treatment is all borrowed from relatives and friends. We have no other choice."

\subsection{Subject 5: Desperate for Knowledge of Patient Care}

Among the participants, except one community doctor who had basic knowledge of patient care, the rest obtained the relevant knowledge mainly from medical staff. The mothers felt frustrated because they thought they were not doing well enough. participant 3: "Your discharge guidance tells us to prevent infection, such as rejecting overnight meals, etc. I don't know how to do it. I feel a little confused." participant 5: "Your guidance says any food is okay as long as it is a plain, high-protein and high-calorie diet. I really don't understand it. I still want to know what I can cook for him... What's more, do you think the disease will relapse?"

Nowadays, network information is very accessible, but this also made the mothers puzzled. Here are the descriptions of the interviewees. participant 2: "I often search the Internet for the information I want. For example, when I was not clear 
about whether to feed him mushrooms, such as needle mushroom, I searched the Internet and found many people said these are anti-cancer food. So should I feed him mushrooms? How much can he eat?"

\subsection{Subject 6: Desperate for Psychosocial Support}

\subsubsection{Support from Relatives}

Considering the particularity of the Chinese society, it is often the participant that a big family live together. participant 4 : "So far, the money is raised by the clan members. This is typical of Chaozhou people." participant 9: "The youngest child is left in our hometown, and looked after by her grandparents. There is no alternative."

\subsubsection{Support from Peers}

Because of the developed network and the wide application of WeChat nowadays, many parents of children treated at the same time set up several support groups to discuss medical treatmnt, diet, difficulties and so on. participant 6: "I don't talk much about the disease with my friends, since they don't understand it." participant 7: "This group is great. The members discuss the diets of our children and so on. We are facing similar situations."

\subsubsection{Yearning for Professional Support, and Worried about the Disability of Child}

Almost all the respondents were concerned about recurrence, subsequent growth and development, and the function of nervous system after recovery (all the 9 children underwent radiotherapy and chemotherapy of expected 6 - 8 courses). participant 2: "Can her growth retardation get improved after treatment?". participant 3: "My child will be blind forever, right?". participant 5: "The disease will not recur after treatment, right? Although the doctor has explained to me many times, I just cannot understand it."

\section{Discussion}

\subsection{Mothers of Children with Malignant Brain Tumors Have Special Emotional Experiences}

Children with malignant brain tumors have poor prognosis, and their growth and development and nerve function are threatened, which is, for parents, a threat to the life safety and health of children. In this study, the mothers felt sad, guilty and powerless, which is consistent with the study of Litzelman [8] et al. Compared with the parents of healthy children, the parents of children with brain tumors are more likely to feel depressed and have poorer quality of life. The worse function the child has, the worse experience the parents have. In this study, 5 children had developmental retardation. One of them suffered poor muscle strength and blindness, so his mother cried in the interview. The cost of surgery, radiotherapy and chemotherapy is another cause of maternal stress. The study of Litzelman [8] suggests that a higher education level means a worse quality of life 
for the mothers, which is contrary to this study. In this study, participants with a higher level of education got more support.

\subsection{Mothers of Children with Malignant Brain Tumors Have Urgent Needs for Knowledge of Patient Care and Professional Support}

In this study, all participants including the community doctor had an urgent need for knowledge of patient care and professional support. Previous studies have found that primary caregivers whose basic needs are better satisfied are less likely to feel depressed. In this study, although the participants were trained on health education and even provided with cautions and tips for hospital discharge every time their children were discharged from hospital, life adaptation and related problems encountered by the mothers in the course of home care often exceeded the care of medical staff, so that the mothers felt stressed, anxious and uncertain. This requires medical staff to spend more time and energy on targeted health education for the mothers as the primary caregivers.

\subsection{Peers Are Good Supporters}

In this study, most mothers received more or less peer support from parents of other children with malignant brain tumors. Social support from family members and friends was a significant predictor of social well-being [9]. Depressive symptoms were significantly associated with social media usage, social support [10]. Today, developed network and social media like WeChat and QQ facilitate the communication between peers. Improving the health literacy of caregivers effectively improved their care ability, and that social support was important for the link between health literacy and care ability [11]. Nursing staff should encourage or help parents to set up social support systems to help them get it through.

\subsection{Positive Self-Adjustment}

Studies have shown that the sense of benefit of caregivers is related to the disease-related factors of the caregivers, including the type of disease, daily activity ability, treatment mode, prognosis of the disease, and duration of the disease [12] [13] [14]. This study found that mothers in the process of taking care of their sick children, gradually knew how to self-adjust and accept the fact. With the development of the situation of the child, the mother's mood changed.

This study has its limitations. The results of this study lack analogies, and there may be bias in data extraction and interpretation analysis. To sum up, this study focused on a special group-the mothers of children with malignant brain tumors, and explored their special feelings and inner experiences during chemotherapy of their children. Most mothers expressed their huge mental stress and an urgent need for knowledge and professional support of patient care. The presentation of the emotional experiences of mothers of children with malignant brain tumors can help medical staff understand their difficulties and needs, and 
provide basis for post-discharge care.

\section{Conflicts of Interest}

The authors declare no conflicts of interest regarding the publication of this paper.

\section{References}

[1] Zhou, Y.-L., An, J.-L. and Tian, L. (2015) Epidemiological Analysis of Childhood Malignant Tumors in China. Chinese Journal of Contemporary Pediatrics, 17, 649654.

[2] Kochanek, K.D., Murphy, S.L. and Xu, J. (2015) Deaths: Final Data for 2011. National Vital Statistics Reports, 63, 1-120.

[3] Brown, R.T., Madan-Swain, A. and Lambert, R. (2003) Posttraumatic Stress Symptoms in Adolescent Survivors of Childhood Cancer and Their Mothers. Journal of Traumatic Stress, 16, 309-318. https://doi.org/10.1023/A:1024465415620

[4] Aung, K.T., Muda, S.M. and Jamaludin, K. (2016) Oncology Nursing: A Preliminary Study on Experiences of Mothers of Childhood Cancer Survivors in Kuantan, Pahang, Malaysia. International Journal of Health Sciences \& Research, 6, 306-316.

[5] Kim, Y. and Given, B.A. (2010) Quality of Life of Family Caregivers of Cancer Survivors: Across the Trajectory of the Illness. Cancer, 112, 2556-2568.

https://doi.org/10.1002/cncr.23449

[6] Wang, J., Zhao, Y.Y., Yang, Q.Y., Sai, K., Ke, C., Zhang, X., et al. (2015) Clinical Analysis of 219 Participants of Central Nervous System Tumor in Children. Guangdong Medical Journal, 36, 2621-2624.

[7] Streisand, R., Mackey, E.R. and Herge, W. (2009) Associations of Parent Coping, Stress, and Well-Being in Mothers of Children with Diabetes: Examination of Data from a National Sample. Maternal \& Child Health Journal, 14, 612-617. https://doi.org/10.1007/s10995-009-0497-7

[8] Litzelman, K., Catrine, K., Gangnon, R. and Witt, W.P. (2011) Quality of Life among Parents of Children with Cancer or Brain Tumors: The Impact of Child Characteristics and Parental Psychosocial Factors. Quality of Life Research, 20, 12611269. https://doi.org/10.1007/s11136-011-9854-2

[9] Leow, K., Lynch, M.F. and Lee, J. (2019) Social Support, Basic Psychological Needs, and Social Well-Being among Older Cancer Survivors. The International Journal of Aging and Human Development, 92, 100-104.

https://doi.org/10.1177/0091415019887688

[10] Wu, F. and Sheng, Y. (2019) Social Support Network, Social Support, Self-Efficacy, Health-Promoting Behavior and Healthy Aging among Older Adults: A Pathway Analysis. Archives of Gerontology and Geriatrics, 85, Article ID: 103934. https://doi.org/10.1016/j.archger.2019.103934

[11] Li, Y.N., Hu, L.Y., Mao, X.E., Shen, Y.J., Xue, H.P., Hou, P., et al. (2020) Health Literacy, Social Support, and Care Ability for Caregivers of Dementia Patients: Structural Equation Modeling. Geriatric Nursing, 41, 600-607.

https://doi.org/10.1016/j.gerinurse.2020.03.014

[12] Pakenham, K.I. and Cox, S. (2008) Development of the Benefit Finding in Multiple Sclerosis (MS) Caregiving Scale: A Longitudinal Study of Relations between Benefit Finding and Adjustment. British Journal of Health Psychology, 13, 583-602.

https://doi.org/10.1348/135910707X250848 
[13] Levesque, J.V. and Maybery, D.J. (2014) Predictors of Benefit Finding in the Adult Children of Patients with Cancer. Journal of Psychosocial Oncology, 32, 535-554. https://doi.org/10.1080/07347332.2014.936646

[14] Cassidy, T. (2013) Benefit Finding through Caring: The Cancer Caregiver Experience. Psychology \& Health, 28, 250-266. https://doi.org/10.1080/08870446.2012.717623 